\title{
Adubação nitrogenada na cultura do milho
}

\author{
Luiz Alberto Navarro de Araújo ${ }^{(1)}$, Manoel Evaristo Ferreira ${ }^{(1)}$ e Mara Cristina Pessôa da Cruz ${ }^{(1)}$
}

(1)Universidade Estadual Paulista, Dep. de Solos e Adubos, Via de acesso Prof. Paulo Donato Castellane, s/no, CEP 14884-900 Jaboticabal, SP.
E-mail: navarroaraujo@ig.com.br, evaristo@fcav.unesp.br, mcpcruz@fcav.unesp.br

Resumo - O uso adequado do fertilizante nitrogenado na cultura irrigada de milho aumenta a produtividade e o lucro, além de reduzir o risco de poluição da água. O objetivo deste trabalho foi determinar a resposta do milho à aplicação de nitrogênio. O experimento foi realizado em Latossolo Vermelho distroférrico típico, de textura argilosa. O delineamento experimental foi em blocos casualizados com parcelas subdivididas e quatro repetições, tendo como tratamento nas parcelas as doses de $\mathrm{N}$ em cobertura $\left(0,60,120,180\right.$ e $\left.240 \mathrm{~kg} \mathrm{ha}^{-1}\right)$, utilizando a uréia e, nas subparcelas, as seqüências de culturas milho-milho-milho e milho-soja-milho. A adubação nitrogenada proporcionou, em relação à testemunha, aumento de $28 \%\left(2.448 \mathrm{~kg} \mathrm{ha}^{-1}\right)$ na produção de grãos de milho. A maior produtividade de grãos, $11.203 \mathrm{~kg} \mathrm{ha}^{-1}$, foi alcançada com a maior dose de $\mathrm{N}\left(240 \mathrm{~kg} \mathrm{ha}^{-1}\right)$. O sistema de rotação não teve efeito na produtividade, mas os teores de $\mathrm{N}$ na massa de matéria seca da parte aérea da planta e nos grãos de milho foram maiores no sistema milho-soja-milho.

Termos para indexação: Zea mays, nitrogênio, irrigação, rotação milho-soja.

\section{Nitrogen fertilization to corn}

\begin{abstract}
Appropriate use of $\mathrm{N}$ fertilizer for irrigated corn increases the yield and the economic return, and it also reduces the risk of water pollution. The objective of this study was to determine corn response to nitrogen. The field experiment was carried out on a clayey typic Haplustox, using a complete split-plot randomized block design with four replications. Nitrogen rates $\left(0,60,120,180\right.$ and $240 \mathrm{~kg} \mathrm{ha}^{-1} \mathrm{~N}$ as urea, in dress application split through the season) were the main plots and the rotation cropping systems, corn-corn-corn and corn-soybeancorn, were the split-plots. Nitrogen fertilization increases the corn yield in $28 \%$ in relation to control. Greatest grain yield, 11,203 $\mathrm{kg} \mathrm{ha}^{-1}$, was obtained with the highest $\mathrm{N}$ rate $\left(240 \mathrm{~kg} \mathrm{ha}^{-1}\right)$. There was no effect of cropping system in grain yield, but $\mathrm{N}$ content in shoot dry matter and in corn grains were larger in corn-soybean-corn system.
\end{abstract}

Index terms: Zea mays, nitrogen, irrigation, corn-soybean rotation.

\section{Introdução}

A produção mundial de milho está em torno de 597 milhões de toneladas, sendo 241 milhões nos Estados Unidos, 114 milhões na China e 35 milhões de toneladas no Brasil (Estados Unidos, 2003). Apesar de o Brasil ser o terceiro maior produtor do cereal, a produtividade média é baixa (de $3.000 \mathrm{~kg} \mathrm{ha}^{-1}$ ) quando comparada com a da China (4.700 $\mathrm{kg} \mathrm{ha}^{-1}$ ) e com a dos Estados Unidos (8.670 kg ha-1).

Entre os fatores responsáveis pela alta produtividade da cultura do milho nos EUA, está o aumento expressivo do uso dos fertilizantes nitrogenados. Segundo Lemaire \& Gastal (1997), o N é o elemento exigido em maior quantidade pelo milho, e é o que mais freqüentemente limita a produtividade de grãos. Enquan- to no Brasil a quantidade utilizada desse nutriente é, em média, de $60 \mathrm{~kg} \mathrm{ha}^{-1}$, na China é de $130 \mathrm{~kg} \mathrm{ha}^{-1}$ e nos Estados Unidos, de $150 \mathrm{~kg} \mathrm{ha}^{-1}$ (International Fertilizer Industry Association, 2002).

Segundo Uhart \& Andrade (1995) e Escosteguy et al. (1997), o N determina o desenvolvimento das plantas de milho, com aumento significativo na área foliar e na produção de massa de matéria seca, resultando em maior produtividade de grãos. A recuperação aparente do $\mathrm{N}$ do fertilizante vem sendo usada como uma estimativa da eficiência da adubação, que decresce com o aumento da dose aplicada. No entanto, segundo Grove (1979), é a recuperação líquida do $\mathrm{N}$, ou seja, o aumento da quantidade de $\mathrm{N}$ na matéria seca da parte aérea por unidade do fertilizante, que melhor relaciona absorção de $\mathrm{N}$ pela cultura com o $\mathrm{N}$ aplicado. 
Outra prática, utilizada no aumento da produtividade, é a da rotação da cultura do milho com a cultura da soja. O cultivo de milho em rotação com a soja produz até $30 \%$ mais do que se cultivado em monocultura, por causa do aporte de $\mathrm{N}$ da leguminosa para a cultura subsequiente (Peterson \& Varvel, 1989; Crookston et al., 1991; Bundy et al., 1993; Omay et al., 1998). Resultados semelhantes, principalmente em anos secos ou em condições de estresse, foram obtidos por Raimbault \& Vyn (1991) e Randall \& Iragavarapu (1995).

Comparações entre as quantidades de $\mathrm{N}$ fixado simbioticamente e retornado ao solo pelos resíduos da soja, com as quantidades de $\mathrm{N}$ removidas na colheita de grãos, sugerem que parte da contribuição do $\mathrm{N}$ atribuída à soja é feita à custa da diminuição do $\mathrm{N}$ disponível do solo (Alvarez et al., 1995; Vanotti \& Bundy, 1995). No entanto, pesquisas que utilizam ${ }^{15} \mathrm{~N}$ têm sugerido que a maior parte do $\mathrm{N}$ da fitomassa das leguminosas tem como destino o solo (Harris \& Hesterman, 1990), ficando acumulado na forma de $\mathrm{N}$ orgânico. A quantidade e distribuição de $\mathrm{N}$ inorgânico, principalmente $\mathrm{NO}_{3}{ }^{-}$, que permanece no perfil do solo, é resultante do fertilizante utilizado, do regime de temperatura e umidade do solo e da aplicação de doses de $\mathrm{N}$ maiores do que as necessárias para atingir produtividades ótimas (Roder et al., 1989; Teixeira et al., 1994; Torbert et al., 1996; Barrios et al., 1998).

O objetivo deste trabalho foi determinar a resposta do milho à aplicação de nitrogênio.

\section{Material e Métodos}

O experimento foi realizado na fazenda Lago Azul ( $20^{\circ} 40^{\prime} \mathrm{S}, 48^{\circ} 15^{\prime} \mathrm{W}$ e altitude $554 \mathrm{~m}$ ), Município de Morro Agudo, SP, em área irrigada por aspersão (pivô central). O solo da área, um Latossolo Vermelho distroférrico típico, de textura argilosa, analisado segundo Camargo et al. (1986) apresentava, em $\mathrm{g} \mathrm{kg}^{-1}$ : argila, 590; limo, 210; areia muito fina, 90; areia fina, 90; e areia média, 20. Foi utilizado, em todos os cultivos, o método reduzido de preparo do solo, com arado escarificador e grade niveladora.

O milho foi cultivado de setembro de 1999 a fevereiro de 2000. No ano agrícola de 2000/2001, a área experimental, $1.634 \mathrm{~m}^{2}$, foi dividida em quatro blocos. Em cada bloco, foram distribuídas cinco parcelas, correspondentes a cinco doses de $\mathrm{N}$, com $8 \mathrm{~m}$ de largura por $7 \mathrm{~m}$ de comprimento. Da divisão da parcela, no sentido da largura, obtiveram-se as subparcelas $(4 \times 7 \mathrm{~m})$ utilizadas na rotação milho-milho ou milho-soja. Entre os blocos e as parcelas, foram mantidos carreadores com $3 \mathrm{~m}$ e $2 \mathrm{~m}$ de largura, respectivamente. Em março de 2000, foi semeada soja, cultivar Conquista MG/BR46 $\mathrm{e}$, em maio, o milho, segundo os tratamentos. As populações foram de 450.000 e 60.000 plantas ha $^{-1}$, utilizando espaçamento de 0,4 e $0,8 \mathrm{~m}$ nas entrelinhas de soja e milho, respectivamente. As adubações foram feitas com base nos resultados de análise de solo e nas expectativas de produtividades. A soja foi colhida em junho e o milho, em outubro. A resteva da cultura da soja foi mantida na subparcela de origem e a do milho, cortada rente ao solo e picada com auxílio de uma enxada rotativa, deixada na respectiva subparcela.

O delineamento experimental empregado foi em blocos casualizados com parcelas subdivididas e quatro repetições. As parcelas tiveram como tratamentos as doses de $\mathrm{N}$ (uréia) aplicado em cobertura, e as subparcelas, duas sequiências de culturas, milho-milhomilho e milho-soja-milho. As doses de $\mathrm{N}$ utilizadas foram $0,0,0,5,1,0,1,5$ e 2,0 vezes o sugerido em Raij \& Cantarella (1996), considerando o solo como sendo de alta resposta à adubação nitrogenada e expectativa de produtividade de grãos entre 8 e $10 \mathrm{t} \mathrm{ha}^{-1}$, correspondendo às doses $0,60,120,180$ e $240 \mathrm{~kg} \mathrm{ha}^{-1}$ de nitrogênio.

Em outubro de 2000, procedeu-se à amostragem de solo, coletando-se 20 amostras simples por amostra composta, na camada de 0 a 0,2 $\mathrm{m}$ de profundidade, de cada subparcela, a fim de avaliar a fertilidade do solo antes da instalação do experimento. Parte das amostras foi destinada à determinação de $\mathrm{NH}_{4}{ }^{+} \mathrm{e}$ de $\mathrm{NO}_{3}{ }^{-}$, conforme Silva et al. (1999). A outra parte das amostras foi destinada à análise de rotina, segundo Raij et al. (1987).

Em novembro de 2000, foi semeado o milho, genótipo Cargill 333 B, um híbrido simples de ciclo normal, 950 U.C., no espaçamento de $0,8 \mathrm{~m}$ nas entrelinhas e 8 a 10 sementes/m e, após 15 dias, foi feito o desbaste para 70.000 plantas ha ${ }^{-1}$. A adubação na semeadura foi feita de acordo com Raij \& Cantarella (1996), com base na média geral dos resultados da análise de solo (Tabela 1) e na expectativa de produtividade de 8 a $10 \mathrm{t} \mathrm{ha}^{-1}$ de grãos, para solo classificado como de alta resposta a nitrogênio com 30, 50, 50 e $36 \mathrm{~kg} \mathrm{ha}^{-1}$ de $\mathrm{N}, \mathrm{P}_{2} \mathrm{O}_{5}, \mathrm{~K}_{2} \mathrm{O}$ e $\mathrm{S}$, respectivamente. $\mathrm{O}$ parcelamento do $\mathrm{N}$ foi feito em razão das fases de desenvolvimento da cultura, segundo Resende et al. (1990) (Tabela 2).

No estádio de pendoamento do milho, foi colhida de cada subparcela a parte aérea de cinco plantas, que foi lavada, secada, pesada e moída para a avaliação do teor de $\mathrm{N}$ na planta. 
Em abril de 2001, foi avaliada a produtividade de grãos de milho, colhendo-se três linhas centrais de cada subparcela, descartando-se $1 \mathrm{~m}$ de cada extremidade. O peso de grãos foi corrigido para $14 \%$ de umidade. Na determinação do $\mathrm{N}$ nos grãos do milho, o método semimicro-Kjeldahl foi utilizado, conforme Sarruge \& Haag (1974). Após a colheita, o solo das subparcelas foi amostrado, em 20 subamostras por amostra, nas profundidades de $0-0,2$ e 0,2-0,4 m, para caracterização química. A recuperação do fertilizante nitrogenado foi calculada subtraindo o $\mathrm{N}$ removido na parcela-testemunha do $\mathrm{N}$ removido nas outras parcelas, dividido pela quantidade de $\mathrm{N}$ aplicado em cada uma delas e multiplicado por 100, conforme citado por Omay et al. (1998).

Os dados foram submetidos a análises de variância, de regressão e de correlação, de acordo com os procedimentos do Statistical Analysis System (SAS Institute, 1990). Na comparação das médias, foi usado o teste de Tukey a $5 \%$ de probabilidade.

\section{Resultados e Discussão}

Houve efeito das doses de $\mathrm{N}$ na produtividade, nos teores e quantidade total de $\mathrm{N}$ nos grãos e na massa de matéria seca da parte aérea da planta (Tabela 3). A rotação de culturas afetou os teores de $\mathrm{N}$ na matéria seca e nos grãos. Os valores observados foram menores nos tratamentos em que a cultura anterior foi o milho.
A diferença entre a produção de matéria seca na testemunha e a obtida com a maior dose de $\mathrm{N}\left(240 \mathrm{~kg} \mathrm{ha}^{-1}\right)$ foi de $37 \%$. O teor de $\mathrm{N}$ contido na matéria seca da parte aérea (MSPA), em função das doses de $\mathrm{N}$ aplicadas, aumentou proporcionalmente mais do que o total extraído pela planta, principalmente nas doses menores. A quantidade máxima de $\mathrm{N}$ no grão foi obtida com a dose de $120 \mathrm{~kg} \mathrm{ha}^{-1}$ de $\mathrm{N}$, enquanto na MSPA, foi com $240 \mathrm{~kg} \mathrm{ha}^{-1} \mathrm{de} \mathrm{N}$, indicando uma tendência ao consumo de luxo de $\mathrm{N}$ pela planta, conforme já relatado por Uhart \& Andrade (1995). Não houve efeito da adubação nitrogenada no teor de $\mathrm{N}$ dos grãos; contudo, a quantidade total de $\mathrm{N}$ nos grãos aumentou de 131 até $176 \mathrm{~kg} \mathrm{ha}^{-1}$ e esteve entre 14,9 e $16 \mathrm{~kg}$ de $\mathrm{N}$ por tonelada de grãos, com valores próximos aos $17 \mathrm{~kg} \mathrm{t}^{-1}$ citados em Raij et al. (1996).

Os dois sistemas removeram mais $\mathrm{N}$ quando altas doses foram aplicadas, sem diferença entre sistemas (Tabela 3). Nas parcelas-testemunha, em monocultura, o milho removeu $217 \mathrm{~kg} \mathrm{ha}^{-1}$ de $\mathrm{N}$ e, em rotação, $223 \mathrm{~kg} \mathrm{ha}^{-1} \mathrm{de} \mathrm{N}$; com a dose de $60 \mathrm{~kg} \mathrm{ha}^{-1}$ de N, $254 \mathrm{e}$ 256; com a dose de $120 \mathrm{~kg} \mathrm{ha}^{-1}$ de N, 264 e 286; com a dose de $180 \mathrm{~kg} \mathrm{ha}^{-1}$ de N, 295 e 308, e com a dose de $240 \mathrm{~kg} \mathrm{ha}^{-1} \mathrm{de} \mathrm{N}, 330$ e 344 , respectivamente. Resultados semelhantes foram observados por Torbert et al. (1996), e são atribuídos à maior atividade radicular das plantas de milho cultivadas após a soja do que após o

Tabela 1. Análise química de solo das subparcelas antes da aplicação das doses de nitrogênio.

\begin{tabular}{|c|c|c|c|c|c|c|c|c|c|c|c|c|}
\hline \multirow{2}{*}{$\underset{\left(\mathrm{kg} \mathrm{ha}^{-1}\right)^{(1)}}{\mathrm{N}}$} & \multicolumn{2}{|r|}{$\mathrm{P}_{\text {(resina) }}$} & \multicolumn{2}{|r|}{$\mathrm{pH}_{\mathrm{CaCl} 2}$} & \multicolumn{2}{|r|}{$\mathrm{K}^{+}$} & \multicolumn{2}{|r|}{$\mathrm{Ca}^{2+}$} & \multicolumn{2}{|c|}{$\mathrm{Mg}^{2+}$} & \multicolumn{2}{|c|}{$\mathrm{H}+\mathrm{Al}$} \\
\hline & Milho & Soja-milho & Milho & Soja-milho & Milho & Soja-milho & Milho & Soja-milho & Milho & Soja-milho & Milho & Soja-milho \\
\hline & \multicolumn{4}{|c|}{$----\left(\mathrm{mg} \mathrm{dm}^{-3}\right)---$} & \multicolumn{8}{|c|}{ 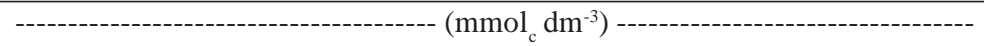 } \\
\hline 0 & 145 & 142 & 5,8 & 5,8 & 4,7 & 4,2 & 52 & 50 & 13 & 14 & 31 & 30 \\
\hline 60 & 151 & 160 & 5,9 & 6,0 & 4,9 & 4,2 & 59 & 65 & 17 & 18 & 29 & 26 \\
\hline 120 & 141 & 162 & 6,0 & 5,9 & 4,8 & 4,5 & 56 & 60 & 16 & 17 & 25 & 28 \\
\hline 180 & 150 & 153 & 6,0 & 5,9 & 4,7 & 4,6 & 61 & 59 & 17 & 17 & 27 & 30 \\
\hline 240 & 156 & 154 & 5,7 & 6,0 & 4,9 & 4,1 & 52 & 65 & 15 & 18 & 33 & 26 \\
\hline
\end{tabular}

${ }^{(1)}$ Doses de $\mathrm{N}$ que foram posteriormente aplicadas.

Tabela 2. Parcelamento da aplicação de nitrogênio em cobertura e doses utilizadas.

\begin{tabular}{|c|c|c|c|c|c|}
\hline \multirow[t]{2}{*}{ Fases de desenvolvimento do milho(1) } & \multicolumn{5}{|c|}{ Tratamentos $^{(2)}$} \\
\hline & $\mathrm{N}_{0}$ & $\mathrm{~N}_{0,5}$ & $\mathrm{~N}_{1}$ & $\mathrm{~N}_{1,5}$ & $\mathrm{~N}_{2}$ \\
\hline \multicolumn{6}{|c|}{ - } \\
\hline Quatro folhas ${ }^{(3)}$ & 0 & 60 & 60 & 60 & 60 \\
\hline Oito folhas ${ }^{(3)}$ & 0 & 0 & 20 & 40 & 60 \\
\hline Doze folhas ${ }^{(3)}$ & 0 & 0 & 20 & 40 & 60 \\
\hline Pendoamento & 0 & 0 & 20 & 40 & 60 \\
\hline Total & 0 & 60 & 120 & 180 & 240 \\
\hline
\end{tabular}

${ }^{(1)}$ Resende et al. (1990). (2) $\mathrm{N}_{0}, \mathrm{~N}_{0.5}, \mathrm{~N}_{1}, \mathrm{~N}_{1,5}$ e $\mathrm{N}_{2}$ correspondem a submúltiplos e múltiplos da dose recomendada, em cobertura com $\mathrm{N}$, para produtividade entre 8 e $10 \mathrm{t} \mathrm{ha}^{-1}$ e classe alta de resposta a N (Raij \& Cantarella, 1996). (3)Folhas recém-maduras (lígula visível). 
milho. Segundo esses autores, a rotação melhora as condições físicas do solo, promovendo o crescimento de raízes e melhor uso do $\mathrm{N}$ do solo e do fertilizante. A eficiência no uso do fertilizante nitrogenado variou de $39 \%$ a $62 \%$ no milho em monocultura e de $47 \%$ a $56 \%$ no milho em rotação com soja, valores semelhantes aos encontrados por Wienhold et al. (1995), Anderson et al. (1997) e Gentry et al. (2001).

A produtividade de grãos e o total de $\mathrm{N}$ acumulado aumentaram com o aumento das doses de $\mathrm{N}$ aplicadas, e o efeito das doses de $\mathrm{N}$ na produtividade foi linear (Figura 1). Esse aumento indica que a disponibilidade de $\mathrm{N}$ foi limitada nas parcelas-testemunha. A aplicação de $240 \mathrm{~kg} \mathrm{ha}^{-1}$ de $\mathrm{N}$ proporcionou a maior produtividade e, em relação à testemunha, aumento de $2.448 \mathrm{~kg} \mathrm{ha}^{-1}$ (28\%) na produtividade de grãos. Esta dose está próxima das citadas por Cantarella (1993) e por Coelho \& França (2001). O primeiro cita que, em várias partes do mundo, a recomendação de $\mathrm{N}$ para culturas de milho de alta produtividade, ou seja, maior do que $9.000 \mathrm{~kg} \mathrm{ha}^{-1}$, varia de 150 a $300 \mathrm{~kg} \mathrm{ha}^{-1}$, e os segundos recomendam o uso de 100 a $200 \mathrm{~kg} \mathrm{ha}^{-1}$ de $\mathrm{N}$ para a cultura de milho irrigada.

Na monocultura, a quantidade de $\mathrm{N}$ necessária para atingir $90 \%$ da maior produção de grãos estimada pela equação (11.269 $\mathrm{kg} \mathrm{ha}^{-1}$ ) foi de $127 \mathrm{~kg} \mathrm{ha}^{-1}$ de nitrogênio. Na rotação, $90 \%$ da maior produção (11.550 kg ha-1) foi alcançada com $129 \mathrm{~kg} \mathrm{ha}^{-1}$ de nitrogênio. A dose de $120 \mathrm{~kg} \mathrm{ha}^{-1}$ de $\mathrm{N}$ é a recomendada por Raij \& Cantarella (1996) para produção estimada de $8.000 \mathrm{a} 10.000 \mathrm{~kg} \mathrm{ha}^{-1} \mathrm{em}$ solos que permitam à planta alta resposta ao nitrogênio. Vanotti \& Bundy (1994), em um estudo de 24 anos, determinaram que a dose econô- mica variou de $168 \mathrm{~kg} \mathrm{ha}^{-1} \mathrm{de} \mathrm{N}$, em anos de alta produtividade, a $176 \mathrm{~kg} \mathrm{ha}^{-1} \mathrm{de} \mathrm{N}$, em anos de baixa produtividade.

Estes resultados contrastam com a expectativa dos efeitos benéficos da rotação sobre a monocultura na produtividade de grãos de milho (Peterson \& Varvel, 1989; Omay et al., 1998). Uma das prováveis causas da pequena variação na produtividade de grãos entre os sistemas é o teor elevado de matéria orgânica (MO) do solo, no início do experimento (Tabela 4), que sofreu redução com o tempo, e com a profundidade. Como não foram observadas variações significativas nos teores de $\mathrm{MO}$ entre as parcelas que receberam monocultura e rotação, que pudessem refletir desuniformidade na área experimental, pode ter ocorrido efeito na mineralização do $\mathrm{N}$ por causa do preparo do solo, com menor intensidade de sua mobilização. O preparo de solo associado ao sistema de irrigação tende a proporcionar umidade suficiente para a decomposição da matéria orgânica (Sanchez, 1976). Autores têm relatado que sistemas de manejo conservacionistas criam um ambiente no solo diferente do verificado no sistema convencional, com acúmulo superficial de matéria orgânica e de fertilizantes (Schulte \& Bundy, 1985). A utilização do arado escarificador é considerada como preparo conservacionista, pois permite cobertura do solo acima de 30\% (Klein et al., 1995).

Outra provável causa da pequena variação na produtividade de grãos entre os sistemas é o acúmulo de $\mathrm{NO}_{3}{ }^{-}$ no perfil do solo, em anos secos, que poderia alterar o

Tabela 3. Matéria seca da parte aérea (MSPA), produtividade de grãos, teor de nitrogênio nos grãos e quantidade de nitrogênio extraído pela matéria seca da parte aérea e pelos grãos de milho em função das doses de nitrogênio aplicadas e da rotação de culturas $^{(1)}$.

\begin{tabular}{|c|c|c|c|c|c|c|c|}
\hline \multirow{2}{*}{$\begin{array}{c}\text { Dose de N } \\
\left(\mathrm{kg} \mathrm{ha}^{-1}\right)\end{array}$} & \multicolumn{2}{|c|}{ Produção } & \multicolumn{2}{|c|}{ Teor de $\mathrm{N}$} & \multicolumn{3}{|c|}{ N extraído } \\
\hline & MSPA & Grãos & MSPA & Grãos & MSPA & Grãos & Total \\
\hline & \multicolumn{2}{|c|}{------------(kg ha'-1) ------------ } & \multicolumn{2}{|c|}{-------------(g) ----------- } & \multicolumn{3}{|c|}{ 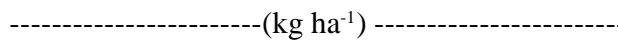 } \\
\hline 0 & $10.558,0 \mathrm{c}$ & $8.755,4 d$ & $7,94 d$ & $14,93 \mathrm{a}$ & $83,80 \mathrm{~d}$ & $130,80 \mathrm{c}$ & $214,60 \mathrm{e}$ \\
\hline 60 & $11.583,3 \mathrm{bc}$ & $9.741,0 \mathrm{c}$ & $8,89 \mathrm{c}$ & $15,08 \mathrm{a}$ & $103,38 \mathrm{~cd}$ & $147,01 b$ & $250,40 d$ \\
\hline 120 & $12.276,9 \mathrm{bc}$ & $10.246,8 b c$ & $9,75 b$ & $15,52 \mathrm{a}$ & $119,76 b c$ & $163,57 \mathrm{a}$ & $283,33 c$ \\
\hline 180 & $13.279,5 \mathrm{ab}$ & $10.974,0 \mathrm{ab}$ & $10,11 b$ & $15,72 \mathrm{a}$ & $134,46 b$ & $170,32 \mathrm{a}$ & $304,80 \mathrm{~b}$ \\
\hline 240 & $14.482,6 \mathrm{a}$ & $11.203,3 \mathrm{a}$ & $10,95 \mathrm{a}$ & $15,97 \mathrm{a}$ & $158,76 \mathrm{a}$ & $176,23 \mathrm{a}$ & $335,00 \mathrm{a}$ \\
\hline Milho-milho & $12.297,0 \mathrm{a}$ & $10.068,0 \mathrm{a}$ & $9,28 b$ & $15,24 b$ & $116,32 \mathrm{a}$ & $155,70 \mathrm{a}$ & $275,80 \mathrm{a}$ \\
\hline Soja-milho & $12.575,0 \mathrm{a}$ & $10.300,2 \mathrm{a}$ & $9,78 \mathrm{a}$ & $15,64 \mathrm{a}$ & $123,74 a$ & $159,48 \mathrm{a}$ & $281,39 \mathrm{a}$ \\
\hline Dose $\mathrm{x}$ rotação & $0,14^{\mathrm{ns}}$ & $0,64^{\mathrm{ns}}$ & $0,28^{\mathrm{ns}}$ & $3,03^{\mathrm{ns}}$ & $0,31^{\mathrm{ns}}$ & $1,94^{\mathrm{ns}}$ & $1,35^{\mathrm{ns}}$ \\
\hline $\mathrm{CV}(\%)$ & 8,52 & 5,36 & 5,08 & 3,75 & 11,33 & 6,87 & 6,55 \\
\hline
\end{tabular}

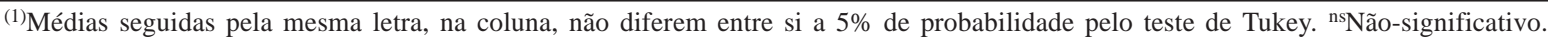


efeito do N proveniente da leguminosa (Randall \& Iragavarapu, 1995). Dados climáticos da área experimental indicam uma temperatura média de $24^{\circ} \mathrm{C}$ e precipitação de $1.491 \mathrm{~mm}$ durante o período experimental (outubro de 2000 a abril de 2001) e uma temperatura média de $20^{\circ} \mathrm{C}$ e precipitação pluvial de $790 \mathrm{~mm}$ no período de maio a outubro de 2000, anterior à instalação do experimento. Esse período foi marcado pelo menor volume de chuvas, na região, nos últimos 10 anos. Tais condições sugerem que parte do $\mathrm{NO}_{3}{ }^{-}$contido nas amostras de solo é originária do $\mathrm{N}$ orgânico, mineralizado e acumulado no perfil do solo. Segundo Barrios et al. (1998), em região de clima quente e seco, embora a percolação da água no solo seja mínima, a mineralização do $\mathrm{N}$ continua a ocorrer, havendo acúmulo de $\mathrm{NH}_{4}{ }^{+}$antes do período das chuvas, com rápida conversão de $\mathrm{NH}_{4}{ }^{+}$ para $\mathrm{NO}_{3}{ }^{-}$no início do período úmido. A adversidade das condições climáticas durante o período experimental foi menos evidente, e o desenvolvimento da cultura foi normal para a época e região, exceto no mês de

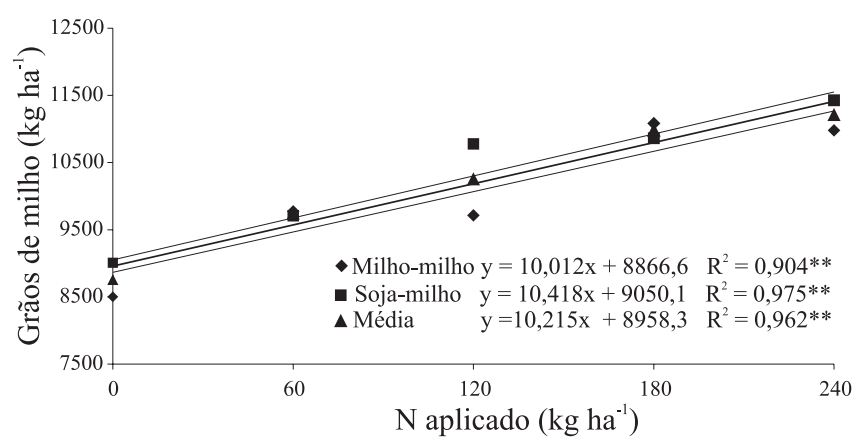

Figura 1. Produtividade de grãos de milho de acordo com doses de nitrogênio aplicadas. novembro (semeadura), quando o volume de chuvas ultrapassou a média histórica de dez anos da região.

De acordo com Escosteguy et al. (1997), são necessários $20 \mathrm{~kg} \mathrm{ha}^{-1}$ de $\mathrm{N}$ para produção de $1.000 \mathrm{~kg} \mathrm{ha}^{-1}$ de grãos de milho. Assim, para a quantidade de grãos produzida na parcela-testemunha $\left(8.755 \mathrm{~kg} \mathrm{ha}^{-1}\right)$, estima-se que o suprimento de $\mathrm{N}$ do solo foi cerca de $174 \mathrm{~kg} \mathrm{ha}^{-1}$. A contribuição de $\mathrm{N}$ do solo, com a suplementação hídrica, pode ter influenciado a resposta dos tratamentos, possibilitando alta produtividade da testemunha e dos sistemas estudados. Resultados semelhantes foram observados por Escosteguy et al. (1997).

Houve redução significativa ( $82 \%$ ) nos teores originais de $\mathrm{NO}_{3}$ - durante o período experimental (Tabela 4). A mudança nesses teores revela a mobilidade do $\mathrm{NO}_{3}{ }^{-}$ no solo ( $18 \%$ retidos nas camadas de 0 a $0,2 \mathrm{~m}$ e $22 \%$ na de 0,2 a $0,4 \mathrm{~m}$ de profundidade). Em virtude das condições climáticas durante o período experimental, era esperado que a lixiviação do $\mathrm{NO}_{3}{ }^{-}$ocorresse nas parcelas que receberam as maiores doses de $\mathrm{N}$, mas os dados indicam uma elevada capacidade de mineralização deste solo em condições de alternância de períodos secos e úmidos. As reduções, nos valores de $\mathrm{NO}_{3}{ }^{-}$, são semelhantes às encontradas por Randall \& Iragavarapu (1995). Segundo esses autores, em anos secos, as perdas foram inferiores a $3 \%$ do $\mathrm{N}$ aplicado e, nos chuvosos, variaram de $25 \%$ a $70 \%$. Esses resultados discordam do citado em Coelho \& França (2001), segundo os quais, a baixa intensidade de nitrificação e de perdas por lixiviação, nos perfis dos solos de textura média e argilosa, não justifica mais do que uma única adubação nitrogenada em cobertura, aos 35 ou 40 dias após o plantio.

Tabela 4. Teores de matéria orgânica $(\mathrm{MO})$ e de nitrato $\left(\mathrm{NO}_{3}^{-}\right)$das subparcelas.

\begin{tabular}{|c|c|c|c|c|c|c|c|c|c|c|c|c|}
\hline \multirow{4}{*}{$\begin{array}{c}\mathrm{N} \\
\left(\mathrm{kg} \mathrm{ha}^{-1}\right)\end{array}$} & \multirow{2}{*}{\multicolumn{4}{|c|}{$\begin{array}{c}\text { Antes da aplicação de } \mathrm{N} \\
\text { Camada de } 0 \text { a } 0,2 \mathrm{~m}\end{array}$}} & \multicolumn{8}{|c|}{ Depois da aplicação de $\mathrm{N}$} \\
\hline & & & & & \multicolumn{4}{|c|}{ Camada de 0 a $0,2 \mathrm{~m}$} & \multicolumn{4}{|c|}{ Camada de 0,2 a $0,4 \mathrm{~m}$} \\
\hline & \multicolumn{2}{|r|}{$\mathrm{MO}$} & \multicolumn{2}{|c|}{$\mathrm{NO}_{3}^{-}$} & \multicolumn{2}{|c|}{$\mathrm{MO}$} & \multicolumn{2}{|r|}{$\mathrm{NO}_{3}^{-}$} & \multicolumn{2}{|r|}{$\mathrm{MO}$} & \multicolumn{2}{|r|}{$\mathrm{NO}_{3}^{-}$} \\
\hline & Milho & Soja-milho & Milho & a-milho & Milho & Soja-milho & Milho & Soja-milho & Milho & Soja-milho & Milho & Soja-milho \\
\hline & \multicolumn{2}{|c|}{---- $\left(\mathrm{g} \mathrm{dm}^{-3}\right)----$} & \multicolumn{2}{|c|}{$-----\left(\mathrm{mg} \mathrm{kg}^{-1}\right)-----$} & \multicolumn{2}{|c|}{---- $\left(\mathrm{g} \mathrm{dm}^{-3}\right)^{-----}$} & \multicolumn{2}{|c|}{----- $\left(\mathrm{mg} \mathrm{kg}^{-1}\right)----$} & \multicolumn{2}{|c|}{$-----\left(\mathrm{g} \mathrm{dm}^{-3}\right)$----- } & \multicolumn{2}{|c|}{----- $\left(\mathrm{mg} \mathrm{kg}^{-1}\right)----$} \\
\hline 0 & 30,2 & 29,5 & 39,4 & 42,1 & 24,0 & 23,5 & 8,6 & 3,7 & 16,2 & 16,5 & 10,8 & 6,9 \\
\hline 60 & 31,5 & 30,7 & 42,2 & 40,0 & 23,5 & 22,7 & 8,6 & 6,9 & 17,2 & 17,5 & 9,0 & 6,5 \\
\hline 120 & 30,5 & 31,0 & 42,4 & 45,0 & 22,2 & 21,7 & 11,0 & 8,1 & 15,7 & 15,7 & 9,9 & 9,5 \\
\hline 180 & 31,5 & 32,2 & 38,6 & 43,1 & 22,0 & 22,7 & 8,9 & 8,0 & 15,7 & 15,5 & 9,3 & 11,3 \\
\hline 240 & 31,7 & 30,7 & 43,5 & 44,1 & 22,7 & 22,7 & 7,0 & 4,9 & 15,5 & 15,2 & 9,0 & 9,6 \\
\hline
\end{tabular}




\section{Conclusão}

A produtividade de grãos e de matéria seca da parte aérea da planta de milho aumenta com a elevação das doses de nitrogênio.

\section{Agradecimento}

À Fapesp pelo financiamento da pesquisa.

\section{Referências}

ALVAREZ, R.; LEMCOFF, J.H.; MERZARI, A.H. Balance de nitrógeno en un suelo cultivado con soja. Ciencia del Suelo, v.13, p.38-40, 1995.

ANDERSON, I.C.; BUXTON, D.R.; KARLEN, D.L.; CAMBARDELLA, C. Cropping system effects on nitrogen removal, soil nitrogen, aggregate stability, and subsequent corn grain yield. Agronomy Journal, v.89, p.881-886, 1997.

BARRIOS, E.; KWESIGA, F.; BURESH, R.J.; SPRENT, J.I.; COE, $\mathrm{R}$. Relating preseason soil nitrogen to maize yield in tree legumemaize rotations. Soil Science Society of America Journal, v.62, p.1604-1609, 1998.

BUNDY, L.G.; ANDRASKI, T.W.; WOLKOWSKI, R.P. Nitrogen credits in soybean-corn crop sequences on three soils. Agronomy Journal, v.85, p.1061-1067, 1993.

CAMARGO, O.A.; MONIZ, A.C.; JORGE, J.A.; VALADARES, J.M.A.S. Métodos de análise química, mineralógica e física de solos do Instituto Agronômico de Campinas. Campinas: Instituto Agronômico, 1986. 94p. (Boletim Técnico, 106).

CANTARELLA, H. Calagem e adubação do milho. In: BÜLL, L.T.; CANTARELLA, H. (Ed.). Cultura do milho: fatores que afetam a produtividade. Piracicaba: Potafos, 1993. p.147-185.

COELHO, A.M.; FRANÇA, G.E. Nutrição e adubação do milho. Disponível em: <http://www.cnpms.embrapa.br/milho/deficiencia/ deficiencia.html> Acesso em: 9 nov. 2001.

CROOKSTON, R.K.; KURLE, J.E.; COPELAND, P.J.; FORD, J.H.; LUESCHEN, W.E. Rotational cropping sequence affects yield of corn and soybean. Agronomy Journal, v.83, p.108-113, 1991.

ESCOSTEGUY, P.A.V.; RIZZARDI, M.A.; ARGENTA, G. Doses e épocas de aplicação de nitrogênio em cobertura na cultura do milho em duas épocas de semeadura. Revista Brasileira de Ciência do Solo, v.21, p.71-77, 1997.

ESTADOS UNIDOS. Department of Agriculture. Foreign Agricultural Service. World agricultural production. Disponível em: <http://www.fas.usda.gov/wap/circular/2003/03-01/wap 0103.pdf.> Acesso em 10 fev. 2003.

GENTRY, L.E.; BELOW, F.E.; DAVID, M.B.; BERGEROU, J.A. Source of the soybean $\mathrm{N}$ credit in maize production. Plant and Soil, v.236, p.175-184, 2001.
GROVE, T.L. Nitrogen fertility in oxisols and ultisols of the humid tropics. Ithaca: Cornell University, 1979. 28p. (Cornell International Agriculture Bulletin, 36).

HARRIS, G.H.; HESTERMAN, O.B. Quantifying the nitrogen contribution from alfalfa to soil and two succeeding crops using nitrogen-15. Agronomy Journal, v.82, p.129-134, 1990.

INTERNATIONAL FERTILIZER INDUSTRY ASSOCIATION (Paris, França). Fertilizer use by crop. 5th ed. Disponível em: <http://www.fertilizer.org>. Acesso em: 9 nov. 2002.

KLEIN, V.A.; BOLLER, W.; CANDATEN, A.; BORTOLOTTI, D.R.; DALPAZ, R.C. Avaliação de escarificadores e resposta da cultura do milho. Revista Brasileira de Ciência do Solo, v.19, p.307-311, 1995.

LEMAIRE, G.; GASTAL, F.N. N uptake and distribution in plant canopies. In: LEMAIRE, G. (Ed.). Diagnosis of the nitrogen status in crops. Berlin: Springer, 1997. p.3-43.

OMAY, A.B.; RICE, C.W.; MADDUX, L.D.; GORDON, W.B. Corn yield and nitrogen uptake in monoculture and in rotation with soybean. Soil Science Society of America Journal, v.62, p.15961603, 1998.

PETERSON, T.A.; VARVEL, G.E. Crop yield as affected by rotation and nitrogen rate. Corn. Agronomy Journal, v.81, p.735-738, 1989.

RAIJ, B. van; QUAGGIO, J.A.; CANTARELLA, H.; FERREIRA, M.E.; LOPES, A.S.; BATAGLIA, O.C. Análise química do solo para fins de fertilidade. Campinas: Fundação Cargill, 1987. 170p.

RAIJ, B. van; CANTARELLA, H. Milho para grãos e silagem. In: RAIJ, B. van; CANTARELLA, H.; QUAGGIO, J.A.; FURLANI, A.M.C. (Ed.). Recomendações de adubação e calagem para o Estado de São Paulo. 2.ed. Campinas: Instituto Agronômico, 1996. p.56-59. (Boletim Técnico, 100).

RAIMBAULT, B.A.; VYN, T.J. Crop rotation and tillage effects on corn growth and soil structural stability. Agronomy Journal, v.83, p.979-985, 1991.

RANDALL, G.W.; IRAGAVARAPU, T.K. Impact of long-term tillage systems for continuous corn on nitrate leaching to tile drainage. Journal of Environmental Quality, v.24, p.360-366, 1995.

RESENDE, M.; ALVES, V.M.C.; FRANÇA, G.E.; MONTEIRO, J.A. Manejo de irrigação e fertilizantes na cultura do milho. Informe Agropecuário, v.14, p.26-34, 1990.

RODER, W.; MASON, S.C.; CLEGG, M.D.; KNIEP, K.R. Yieldsoil water relationships in sorghum-soybean cropping systems with different fertilizer regimes. Agronomy Journal, v.81, p.470-475, 1989.

SANCHEZ, P. Properties and management of soils in the tropics. New York: John Wiley, 1976. 618p.

SARRUGE, J.R.; HAAG, H.P. Análises químicas em plantas. Piracicaba: Esalq, 1974. 55p. 
SAS INSTITUTE (Cary, Estados Unidos). SAS user's guide: statistic. Cary, 1990. 846p.

SCHULTE, E.E.; BUNDY, L.G. Sampling soils for testing under conservation tillage. Better Crops with Plant Food, v.69, p.22-23, 1985.

SILVA, F.C.; EIRA, P.A. da; RAIJ, B. van; SILVA, C.A.; ABREU, C.A.; GIANELLO, C.; PÉREZ, D.V.; QUAGGIO, J.A.; TEDESCO, M.J.; ABREU, M.F.; BARRETO, W. de O. Análises químicas para avaliação da fertilidade do solo. In: SILVA, F.C. da. (Org.). Manual de análises químicas de solos, plantas e fertilizantes. Brasília: Embrapa, 1999.p.75-169. (Embrapa Comunicação para Transferência de Tecnologia).

TEIXEIRA, L.A.J.; TESTA, V.M.; MIELNICZUK, J. Nitrogênio do solo, nutrição e rendimento do milho afetados por sistemas de cultura. Revista Brasileira de Ciência do Solo, v.18, p.207-214, 1994.
TORBERT, H.A.; REEVES, D.W.; MULVANEY, R.L. Winter legume cover crop benefits to corn: rotation vs. fixed-nitrogen effects. Agronomy Journal, v.88, p.527-535, 1996.

UHART, S.A.; ANDRADE, F.H. Nitrogen deficiency in maize. I. Effects on crop growth, development, dry matter partitioning, and kernel set. Crop Science, v.35, p.1376-1383, 1995.

VANOTTI, M.B.; BUNDY, L.G. An alternative rationale for corn nitrogen fertilizer recommendations. Journal of Production Agriculture, v.7, p.243-249, 1994.

VANOTTI, M.B.; BUNDY, L.G. Soybean effects on soil nitrogen availability in crop rotations. Agronomy Journal, v.87, p.676-680, 1995.

WIENHOLD, B.J.; TROOIEN, T.P.; REICHMAN, G.A. Yield and nitrogen use efficiency of irrigated corn in the northern Great Plains. Agronomy Journal, v.87, p.842-846, 1995.

Recebido em 3 de julho de 2003 e aprovado em 19 de março de 2004 